\title{
Detecting Chlamydia trachomatis in men with urethritis: serology $v$ isolation in cell culture
}

\section{Z J HAGAY,* B SAROV, $\dagger$ J SACHS, $\ddagger$ O SHAKED,§ I SAROV§}

From the ${ }^{*}$ Division of Obstetrics and Gynecology, $\dagger$ Epidemiology Unit, $\ddagger$ Laboratory of Clinical Immunology, and the §Virology Unit, Soroka Medical Center and Faculty of Health Sciences, Ben-Gurion University of the Negev, Beer-Sheva, Israel

SUMMARY The accuracy of single serovar (L2) inclusion immunoperoxidase assay (IPA) to show serum IgG and IgA antibodies specific to chlamydiae was compared with culture for Chlamydia trachomatis to diagnose chlamydial infection in 73 men with acute urethritis. $C$ trachomatis only was isolated from $18(25 \%)$, Neisseria gonorrhoeae only from $17(23 \%)$, and both organisms from six $(8 \%)$. Thus $24(33 \%)$ yielded chlamydiae.

Assays based on IgG antibodies to chlamydiae at a titre of $1 / 64$ or more showed high sensitivity $(96 \%)$ and a good negative predictive value ( $80 \%)$, but low specificity $(13 \%)$ and agreement $(48 \%)$ compared with culture. IgG antibodies to chlamydiae at a titre of $1 / 128$ or more showed lower sensitivity $(75 \%)$ but higher specificity $(72 \%)$, negative predictive value $(79 \%)$, and agreement $(73 \%)$. IgA antibodies to chlamydiae at a titre of $1 / 8$ or more showed a sensitivity of $88 \%$, specificity of $72 \%$, negative predictive value of $88 \%$, and agreement of $79 \%$. An appreciable (fourfold or more) decrease in IgA and IgG titres was observed in most (10) of the 15 men from whom second blood samples were obtained one to two years after treatment.

Measuring specific IgA and IgG antibodies to chlamydiae by IPA may serve as a useful complementary test for diagnosing and following up patients with urethritis.

Chlamydia trachomatis is a common transmissible organism that can cause genital diseases ranging from very mild, such as non-gonococcal urethritis (NGU) and postgonococcal urethritis or cervicitis, to severe, such as epididymo-orchitis or acute salpingitis. ${ }^{12}$ The most common presentation of chlamydial infection in men is as NGU. In the USA more than three million cases of NGU are estimated to occur each year, ${ }^{3}$ and a similarly high incidence is reported in England and Wales, where more than 70000 cases are reported each year from clinics for sexually transmitted diseases. ${ }^{4}$ $C$ trachomatis can usually be recovered from $35 \%$ to $60 \%$ of specimens from men with NGU. ${ }^{5}$ The purpose of the present study was to assess the accuracy of a new sensitive serological method (the single serovar (L2) inclusion immunoperoxidase assay (IPA)) for identifying specific chlamydial IgG and IgA antibodies compared with that of the standard method of cell

Address for reprints: Dr I Sarov, Virology Unit, Faculty of Health Sciences, Ben-Gurion University of the Negev, Beer-Sheva 84105, Israel

Accepted for publication 29 December 1988 culture for diagnosing chlamydial infection in men with acute urethritis.

Patients, materials, and methods

STUDY POPULATION

The study was carried out in the southern part of Israel. During the six months from 1 April to 30 September 1985, we systematically investigated all men referred to the sexually transmitted disease (STD) clinic because of urethritis. We performed a clinical examination of and obtained a detailed sexual history, a blood sample, and a urethral swab from each man. All patients were asked to refer their female sexual partners to the clinic, but only $19 \%(14 / 73)$ of them complied. We studied 73 men (mean age 27.6 (range 18-24) years) with symptoms of urethritis. We obtained serum samples for identifying IgG and IgA antibodies to chlamydiae and urethral samples for cultures.

All 73 patients and their female sexual partners were treated with doxycycline $200 \mathrm{mg}$ a day for 14 days and were instructed to use condoms. One to two years after treatment we undertook a clinical and urological study 
of 15 of these patients and obtained further serum samples from them.

\section{MICROBIOLOGICAL METHODS}

Specimens for culture of Neisseria gonorrhoeae were inoculated on to modified Thayer-Martin agar. $N$ gonorrhoeae was identified by a standard method described elsewhere. ${ }^{6}$

Urethral samples for $C$ trachomatis were taken with plastic swabs that were placed in SPG buffer ( $0.01 \mathrm{~mol} / \mathrm{l}$ sodium phosphate, $\mathrm{pH} 7 \cdot 2$, containing $0.25 \mathrm{~mol} / \mathrm{l}$ sucrose and $55 \mathrm{mmol} / \mathrm{l} \mathrm{L}$-glutamic acid) and frozen at $-70^{\circ} \mathrm{C}$ within two hours of collection. For culture, the specimens were inoculated on to cycloheximide treated $\mathrm{McC}$ oy cells and incubated at $36^{\circ} \mathrm{C}$ for 48 hours. $^{7}$ After being incubated, the cells were stained with iodine and examined for typical iodine stained inclusions.

\section{SEROLOGY}

Chlamydia specific IgG and IgA antibodies were detected by a single serovar (L2) inclusion IPA (Ipazyme Chlamydia, Savyon Diagnostics, BeerSheva, Israel) as described previously. ${ }^{8}$ Reactions at IgG titres of $1 / 64$ or more and IgA titres of $1 / 8$ or more were considered to be positive results.

\section{STA TISTICAL ANALYSIS}

Statistical analysis of the results was based on Bayes'

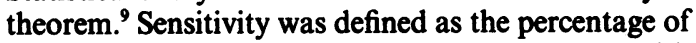
positive results of test for antibody in patients with $C$ trachomatis positive cultures, and specificity was defined as the percentage of negative results of test for antibody in patients with negative cultures. The positive predictive value was defined as the probability that a patient who had a positive serological test result would yield $C$ trachomatis on culture. The negative predictive value was the probability that a patient with a negative result would produce a negative culture. Percentage agreement was defined as follows:

$$
\frac{\text { True positives }+ \text { true negatives }}{\text { Total population }} \times 100
$$

The difference in proportions of positive results for antibody in culture negative versus culture positive patients was evaluated by Fisher's exact test. The differences between the geometric mean titres of the same study groups were evaluated for significance by the $t$ test.

\section{Results}

The results of urethral cultures from the 73 men were as follows: $C$ trachomatis alone was isolated from 18 (25\%), $N$ gonorrhoeae alone from $17(23 \%)$, and both $C$ trachomatis and $N$ gonorrhoeae from six (8\%). Only 14 women (19\% compliance) were referred by their male sexual contacts, so those results are not presented. As the purpose of this study was to evaluate a serological method to detect chlamydiae, the 17 patients yielding $N$ gonorrhoeae only were excluded from analysis. The serological results of these 17 patients did not differ significantly from those of the culture negative patients.

The prevalence of raised titres (1/128 or more) of IgG antibody to chlamydiae was significantly $(\mathrm{p}=0.001)$ higher in patients yielding $C$ trachomatis on culture $(75 \%, 18 / 24)$ than in those not yielding $C$ trachomatis $(28 \%, 9 / 32)$ (table 1$)$. The geometric mean (SE) titre of IgG antibodies in patients positive for IgG antibody to chlamydiae and yielding $C$ trachomatis on culture was $1 / 128(0 \cdot 1)$, higher than in those positive for antibody but negative on culture $(1 / 88(0.09))$, but the difference was of borderline significance $(p=0.07)$.

The results of the test based on specific IgG antibodies to chlamydiae were evaluated in comparison with the culture of $C$ trachomatis from men with

Table 1 Distribution of titres on serology (immunoperoxidase assay) compared with culture results for 56 men with urethritis and positive for IgG antibody to Chlamydia trachomatis

\begin{tabular}{|c|c|c|c|c|}
\hline \multirow[b]{2}{*}{ Results of culture for $C$ trachomatis } & \multicolumn{3}{|c|}{ No (\%) with IgG titres of: } & \multirow{2}{*}{$\begin{array}{l}\text { Geometric } \\
\text { mean (ISE) titre }\end{array}$} \\
\hline & $1 / 64$ & $1 / 128$ & $1 / 256$ & \\
\hline $\begin{array}{l}\text { Positive }(n=24) \\
\text { Negative }(n=32)\end{array}$ & $\begin{array}{l}23(96) \\
28(88)\end{array}$ & $\begin{array}{r}18(75) \\
9(28)\end{array}$ & $\begin{array}{l}5(21) \\
4(13)\end{array}$ & $\begin{array}{l}1 / 128(0 \cdot 1) \\
1 / 88(0 \cdot 09)\end{array}$ \\
\hline $\begin{array}{l}\text { Fisher's exact test } \\
\text { Student's } t \text { test }\end{array}$ & $p=0.279$ & $p=0.001$ & $p=0.32$ & $p=0.07$ \\
\hline $\begin{array}{l}\text { Sensitivity (\%) } \\
\text { Specificity (\%) } \\
\text { Positive predictive value (\%) } \\
\text { Negative predictive value (\%) } \\
\text { Agreement with culture (\%) }\end{array}$ & $\begin{array}{l}96 \\
13 \\
45 \\
80 \\
48\end{array}$ & $\begin{array}{l}75 \\
72 \\
67 \\
79 \\
73\end{array}$ & $\begin{array}{l}21 \\
88 \\
43 \\
56 \\
40\end{array}$ & \\
\hline
\end{tabular}




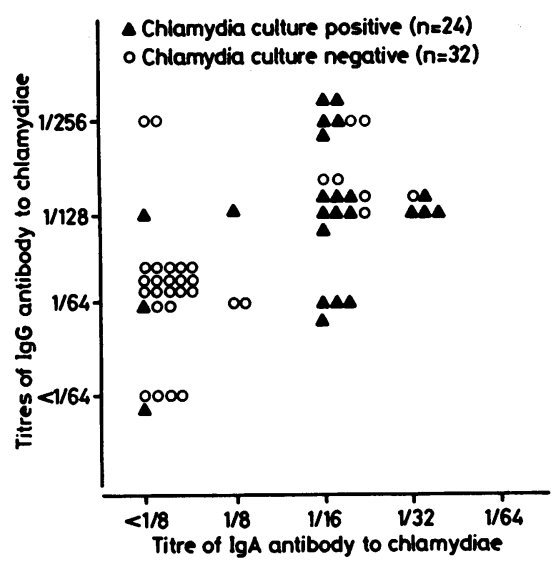

Fig 1 Correlation between titres of $\operatorname{Ig} G$ and $\operatorname{Ig} A$ antibody to chlamydiae on immunoperoxidase assay for 56 patients with urethritis.

urethritis (table 1). The chlamydia IgG test was more sensitive at lower titres $(1 / 64)$, more specific at higher titres $(1 / 128$ or more), and was most accurate at titre of $1 / 128$ or more $(73 \%)$.

The prevalence of titres of $1 / 8$ and $1 / 16$ or more of IgA antibody to chlamydiae was significantly $(\mathrm{p}<0.0001)$ higher in culture positive $(88 \%$ and $83 \%$, respectively) than in culture negative $(28 \%$ and $22 \%$, respectively) patients (table 2). IgA antibodies to chlamydiae were most accurately identified by IPA compared with culture at titres of $1 / 8$ or more $(79 \%)$ and $1 / 16$ or more $(80 \%)$.

Figure 1 shows that all 56 patients with acute urethritis who were $\operatorname{IgA}$ positive with a titre of $1 / 8$ or more were also IgG positive (with a titre of $1 / 64$ or more). High titres (1/128 or more) of IgG antibody to chlamydiae and positive results for IgA antibody were found in $81 \%$ (17) of the 21 patients who yielded chlamydiae on culture and in $78 \%(7 / 9)$ of chlamydia negative patients.

In 15 men with acute urethritis from whom second

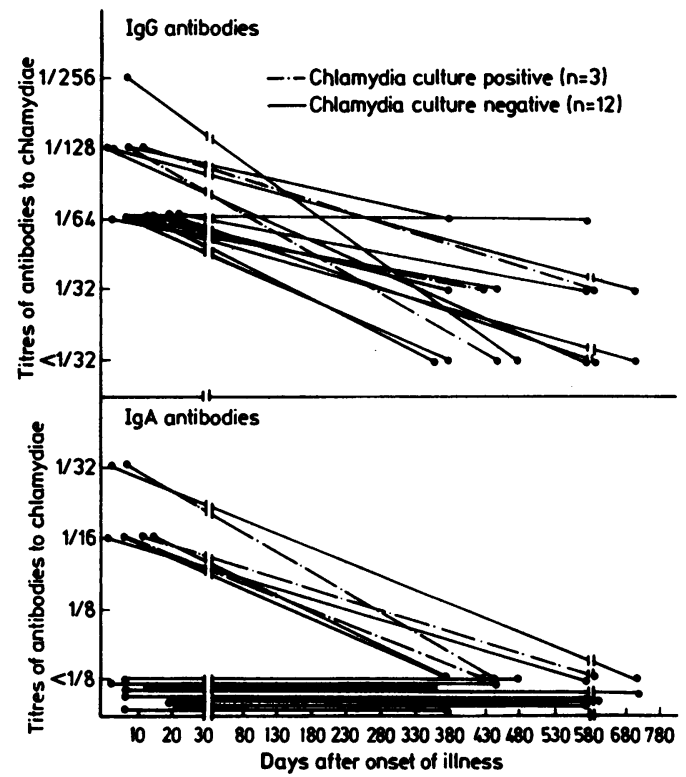

Fig 2 Persistence after one to two years of serum $\operatorname{IgG}$ and IgA antibodies to chlamydiae on immunoperoxidase assay for 15 patients with urethritis.

blood samples were available one to two years after treatment, an appreciable decrease (fourfold or more) in titres of IgG and IgA antibody to chlamydiae was observed (fig 2). A noticeable decrease in titre of IgG antibody to chlamydiae was observed in two out of three patients, who originally yielded chlamydiae on culture. Of the remaining 12 patients, who were chlamydiae negative on their first visit to the STD clinic, IgG antibodies to chlamydiae persisted at stable concentrations in four, whereas the remaining eight showed an appreciable decrease (fourfold or more). The seven patients who gave results for IgA antibodies to chlamydiae at their initial visit (three were culture positive and four negative) gave negative results one to two years after treatment.

Table 2 Distribution of titres on serology (immunoperoxidase assay) compared with culture results for 56 men with urethritis and positive for IgA antibody to Chlamydia trachomatis

\begin{tabular}{|c|c|c|c|c|}
\hline \multirow[b]{2}{*}{ Results of culture for $C$ trachomatis } & \multicolumn{3}{|c|}{ No (\%) with IgA titres of: } & \multirow{2}{*}{$\begin{array}{l}\text { Geometric } \\
\text { mean }(1 S E) \text { titre }\end{array}$} \\
\hline & $1 / 8$ & $1 / 16$ & $1 / 32$ & \\
\hline $\begin{array}{l}\text { Positive }(n=24) \\
\text { Negative }(n=32)\end{array}$ & $\begin{aligned} & 21(88) \\
& 9(28)\end{aligned}$ & $\begin{array}{r}20(83) \\
7(22)\end{array}$ & $\begin{array}{l}4(17) \\
1(3)\end{array}$ & $\begin{array}{l}1 / 18(0.07) \\
1 / 15(0.07)\end{array}$ \\
\hline $\begin{array}{l}\text { Fisher's exact test } \\
\text { Student's } t \text { test }\end{array}$ & $p<0.0001$ & $p<0.0001$ & $\mathrm{p}<0.183$ & $p=0.23$ \\
\hline $\begin{array}{l}\text { Sensitivity }(\%) \\
\text { Specificity }(\%) \\
\text { Positive predictive value (\%) } \\
\text { Negative predictive value }(\%) \\
\text { Agreement with culture }(\%)\end{array}$ & $\begin{array}{l}88 \\
72 \\
70 \\
80 \\
79\end{array}$ & $\begin{array}{l}83 \\
78 \\
74 \\
86 \\
80\end{array}$ & $\begin{array}{l}17 \\
97 \\
80 \\
61 \\
63\end{array}$ & \\
\hline
\end{tabular}




\section{Discussion}

Non-specific urethritis (NSU) is a very common form of urethritis in men. In this study $C$ trachomatis was isolated from $24(33 \%)$ patients with NSU. This incidence was consistent with the results of Schachter, who reported that urethral specimens from about 30 $60 \%$ of patients with NSU yielded $C$ trachomatis. ${ }^{\text {' The }}$ prevalence of culture of $C$ trachomatis from urethral specimens depends on the method of specimen collection, the use of non-toxic endourethral swabs, and the sensitivity of the isolation procedure. The current method of isolating $C$ trachomatis is based on inserting the test swab into the urethra, an invasive and unpleasant procedure. Differences have also been seen in the recovery of the organism from single compared with multiple samples taken from the same anatomical site of one patient at the same time, ${ }^{10}$ and in its recovery from sequential samples taken from one patient at different times. ${ }^{5}$ "1 This may indicate that the sensitivity of chlamydial culture is substantially below $100 \% .^{12}$

Thus serological markers of chlamydial infection seem to be important. The purpose of our study was to evaluate the feasibility of the single serovar (L2) inclusion IPA for IgG and IgA antibodies specific to chlamydiae. The results obtained by the IPA correlated with those obtained by culture for $C$ trachomatis. Chlamydia culture positive men had higher titres (1/128 or more) of chlamydiae specific IgG antibodies than chlamydiae culture negative men (table 1). These results agree with those of Holmes et $a l^{13}$ who also found that significantly raised concentrations of IgG antibodies to chlamydiae occur more often in men with culture positive urethritis than in those who are culture negative. Compared with culture, the presence of chlamydial IgG antibodies at a titre of $1 / 64$ or more showed high sensitivity and negative predictive value, but low specificity and agreement. This can be attributed to the fact that the method was evaluated by isolating $C$ trachomatis from the genital tract. Chlamydial IgG antibodies detected by IPA, shown by using cells infected with $C$ trachomatis (L2) as the antigen, showed broad reactivity. Specific IgG antibodies may indicate current or past chlamydial infection at sites other than the genitourinary tract. ${ }^{14} \mathrm{~A}$ serological technique that would detect only genital strains of $C$ trachomatis would be valuable. Chlamydial IgG antibodies at a titre of $1 / 128$ or more in the IPA (table 1) showed lower sensitivity, but higher specificity, negative predictive value, and agreement than culture.

In the study published here, the finding of specific IgA antibodies to chlamydiae (at a titre of $1 / 8$ or more) in patients with acute urethritis on their first visit to an STD clinic correlated well with the isolation of
C trachomatis from urethral specimens (fig 1). Similar findings have been obtained from patients with urethritis in Italy and Japan. ${ }^{15} 16$

The incidence of specific IgA antibodies to chlamydiae in the IPA in chlamydial culture negative patients was higher $(28 \%)$ than had been found previously in healthy controls $(10 \%)$ of the same age from the same region. ${ }^{17}$ This may indicate that in some cases detecting IgA by IPA may be even more sensitive than isolating $C$ trachomatis. Further studies comparing serology with more sensitive culture methods (by using multiple samples and serial passage) are needed to explore this possibility.

In the study published here we have shown that one to two years after treatment $\operatorname{IgG}$ and $\operatorname{IgA}$ antibodies to chlamydiae had decreased appreciably in (fig 2) chlamydiae culture positive patients with urethritis. Kasamatsu et al prospectively followed up women with cervicitis who yielded chlamydiae on culture; they showed a fall of IgA antibodies to chlamydiae in all but one woman after treatment with tetracycline.$^{18}$ No recurrence of symptoms was reported, but a lack of symptoms does not necessarily exclude the presence of active chlamydial infection. ${ }^{19}$ The importance of specific IgA antibodies as potential markers of effectiveness of treatment needs to be evaluated further in a large number of patients with various chlamydial infections.

In summary, we suggest that titres of IgA and IgG antibody to chlamydiae should be measured in laboratory evaluation of patients with acute urethritis, as some culture positive patients showed raised IgG titres, but no detectable specific IgA (fig 1). Further studies of a larger number of patients with acute urethritis are required to assess the accuracy of the IPA, a non-invasive rapid screening test, in showing IgA and high IgG antibodies to chlamydiae.

\section{References}

1 Ladany S, Sarov I. Recent advances in Chlamydia trachomatis. Eur $J$ Epidemiol 1985;1:235-6.

2 Bruce AW, Chadwick P, Willett WS, O'Shaughnessy M. The role of Chlamydia in genitourinary disease. J Urol 1981;126:625-9.

3 Centers for Disease Control. Chlamydia trachomatis infectionspolicy guidelines for prevention and control. MMWR 1985;34 suppl:35-74.

4 Oriel JD. Epidemiology of genital chlamydia infections. Infection 1982;10 suppl:32-39.

5 Schachter J. Biology of Chlamydia trachomatis. In: Holmes KK, Mårdh P-A, Sparling PE, Wiesner PJ, eds. Sexually transmitted diseases. New York: McGraw-Hill, 1984;243-57.

6 Handsfield HH, Knapp JS, Diehr PK, Holmes KK. Correlation of auxotype and penicillin susceptibility of Neisseria gonorrhoeae with usual preference and clinical manifestation of gonorrhoea. Sex Transm Dis 1980;7:1-5.

7 Ripa KT, Mårdh P-A. Cultivation of Chlamydia trachomatis in cycloheximide-treated McCoy cells. J Clin Microbiol 1970;6:328-32. 
8 Sarov I, Lunenfeld E, Sarov B, et al. Chlamydia specific IgG and IgA antibodies in women with obstructive infertility as determined by immunoblotting and immunoperoxidase assay. Eur J Epidemiol 1988;4:216-23.

9 Bayes T. An assay towards solving a problem in the doctrine of chance. Philos Trans $R$ Soc Lond (Biol) 1969;53:370-418.

10 Goh BT, Dunlop EMC, Darougar S, Woodland R. Three sequential methods of collecting material from the urethra of men for culture for Chlamydia trachomatis. Sex Transm Dis 1985;12:173-6.

11 Jones RB, Katz BP, Van der Pol B, Calne VA, Bateiger BE, Newhall WJ. Effect of blind passage and multiple sampling on recovery of Chlamydia trachomatis from urogenital specimens. J Clin Microbiol 1986;24:1029-33.

12 Ridgway GL. The isolation of Chlamydia species in cell culture. Proceedings of the European Society for Chlamydia Research 1988;1:227-8.

13 Holmes KK, Handsfield NH, Wang S-P, et al. Etiology of nongonoccal urethritis. N Engl J Med 1975;292:1199-205.

14 Forsey T, Stainsby K, Hoger PH, Ridgway GL, Darougar S, Fisher-Brugge U. Comparison of two immunofluorescence tests for detecting antibodies to Chlamydia trachomatis. Eur $J$ Epidemiol 1986;2:163-4.

15 Cevenini R, Sarov I, Rumplanesi F, et al. Serum specific IgA antibodies to Chlamydia trachomatis in patients with chlamydial infections detected by ELISA and immunofiuorescence test. J Clin Pathol 1984;37:686-91.

16 Yoshizawa H, Haraziri N, Hashizume S. Specific serum IgA antibodies in diagnosis of Chlamydia trachomatis infection. Journal of the Japanese Association of Infectious Diseases 1987;61:893-9.

17 Kaneti J, Sarov B, Sarov I. IgG and IgA antibodies specific for Chlamydia trachomatis in acute epididymitis. Eur Urol 1988;14:323-7.

18 Kasamatsu T, Yokoto H, Mizuno N. Evaluation of antichlamydial IgA antibodies in the treatment of female genital tract chlamydial infections. Acta Obstetrica et Gynecologica Japonica 1987;9:1649-50.

19 Stamm WE, Holmes KK. Chlamydia trachomatis infections of the adult. In: Holmes KK, Mårdh P-A, Sparling PF, Wiesner PJ, eds. Sexually transmitted diseases. New York: McGraw-Hill, $1984 ; 258-80$. 